13. Filimonikhin, G. Investigation of the possibility of balancing aerodynamic imbalance of the impeller of the axial fan by correction of masses [Text] / G. Filimonikhin, L. Olijnichenko // Eastern-European Journal of Enterprise Technologies. - 2015. - Vol. 5, Issue 7 (77). - P. 30-35. doi: 10.15587/1729-4061.2015.51195

14. Goncharov, V. An increase of the balancing capacity of ball or roller-type auto-balancers with reduction of time of achieving autobalancing [Text] / V. Goncharov, G. Filimonikhin, A. Nevdakha, V. Pirogov // Eastern-European Journal of Enterprise Technologies. - 2017. - Vol. 1, Issue 7 (85). - P. 15-24. doi: 10.15587/1729-4061.2017.92834

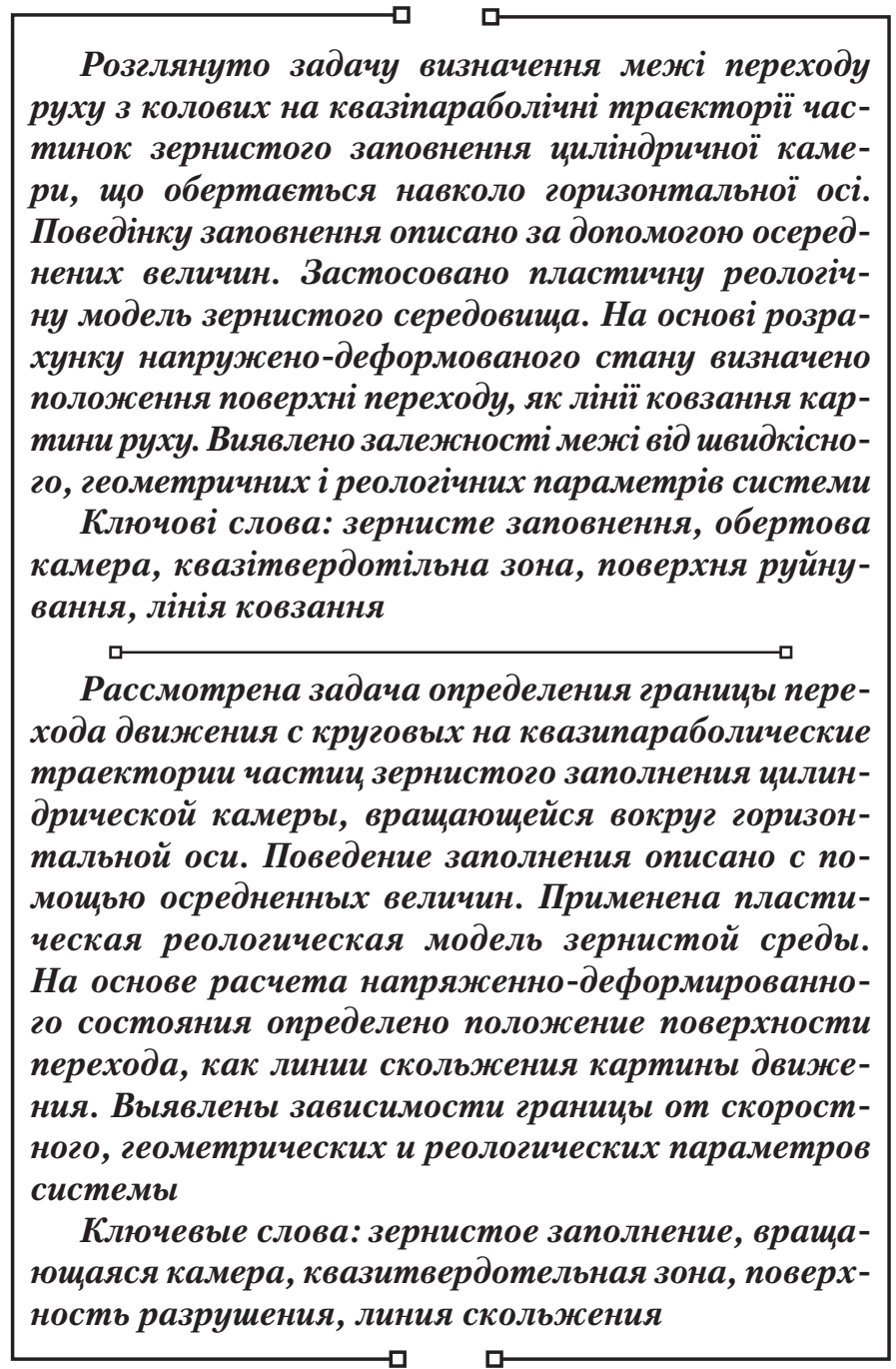

UDC $621.926 .5: 539.215$

DOI: $10.15587 / 1729-4061.2017 .96447$

\section{MODELING OF FRACTURE SURFACE OF THE QUASI SOLID-BODY ZONE OF MOTION OF THE GRANULAR FILL IN A ROTATING CHAMBER}

\author{
Y u. N a u me n ko \\ Doctor of Technical Sciences, Associate Professor \\ Department of construction, road, reclamation, \\ agricultural machines and equipment \\ National University of Water and \\ Environmental Engineering \\ Soborna str., 11, Rivne, Ukraine, 33028 \\ E-mail: informal9m@i.ua
}

\section{Introduction}

The main equipment in the large-tonnage processing of granular materials in chemical, mining, metallurgical, building materials industry, power engineering and many other sectors of industrial production is still traditional machines of the drum type [1]. The main varieties of such a wide class of machines are rotary kilns [2] and coolers [3], drying drums [4], ball [5] and tube [6] mills.

A total number of different materials, which annually undergo processing in such machines in the world, are several tens of billions of tons. A widespread use of machines of this class is due to the possibility of their large performance capacity, reliability in operation, ease of use, versatility and high efficiency.

However, a paradoxical feature of this technological equipment is the combination of the utmost simplicity of design and behavior of the treated medium, which is extremely difficult to describe. Significant difficulties in predicting the implementation of processes in drum machines considerably limit a possible technological scope of their application.

Given that the implementation of working processes in the drum-type machines is predetermined by the character of motion mode of the treated granular material in a chamber, the task on establishing the patterns of change in the parameters of this mode appears to be rather relevant.

\section{Literature review and problem statement}

Motion modes of granular fill in the rotating chambers significantly affect the realization of technological processes and energy efficiency of the drum-type machines drive [7]. 
Modeling of such modes is of interest in the examination of various rotating systems [8].

A practical relevance of the task for predicting the working processes of these machines constantly attracts increased research attention to the description of behavior of the treated granular media. An enhanced complexity of this problem forces to improve traditional techniques as well as to apply new theoretical and experimental methods.

Many attempts were made to numerically solve the problem on determining the motion of granular fill in a rotating cylindrical chamber. The modeling of motion modes of the fill in a wide range of variations in the degree of filling and rotation velocity of a chamber, using the method of discrete elements, was performed in [9]. Parameters of dense two-dimensional established granular flow in a chamber were described in [10] based on the Euler modeling with the Boussinesq approximation. Article [11] presents results of numerical modeling of a three-dimensional non-established flow of active layer of granular particles under the rolling over mode, which was based on the theory of Euler biphase flow and kinetic theory of granular flow. An intermediate, between the cascade and cataract modes, granular flow at the values of filling degree of a chamber at 0.5 and the Froude number of 0.56 , employing the method of discrete elements, was examined in [12]. Results of testing and verifying the source data, with the application of the method of discrete elements, for modeling the motion of granular fill in a rotating chamber, are presented in [13]. Two motion modes of granular fill with a flat and a curved free surface were explored in [14] based on the theory of deep integration that was applied for non-dense flows. In [15], using the method of discrete elements, authors obtained characteristics of the distribution of active and passive zones of a three-dimensional motion of granular fill in a chamber.

However, the initial conditions of the examined problem are a priori uncertain while the boundary conditions are of non-physical nature. This causes a significant constraint for the accuracy of numerical calculations, the results of which do not meet practical requirements.

The motion of granular loading in a rotating chamber was also investigated by various experimental methods. Dynamic characteristics and velocity fields of granular fill were determined, based on the method of the visualization of flow pictures in the cross-section of a chamber, in [16].

Limited capabilities for a visual analysis of behavior of the fill predetermined a widespread use of positron-emission methods of tomographic analysis. Article [17] examined dynamics of non-spherical particles in a rotating chamber using the method of radioactive particles. The application of such technique to establish trajectories of particles under the rolling over mode is described in [18].

The application of positron-emission observation of particles to assess the impact of variations in the speed of chamber rotation on the flow mode of spherical particles is described in [19]. Testing of a new high-precision method of positron-emission particle observation for determining the spatial and temporal kinematic characteristics of a granular flow is covered in [20]. The behavior of active and passive layers of cylindrical and spherical particles in a rotating chamber, using the method of multiple radioactive tracking of particles, was studied in [21]. [22] describes characteristics of the flow of granular loading in drum mills near free surface at big Froude numbers for the cascade and cataract motion modes that were measured by using the positron-emission particle tracking.
A comparison of results in determining the parameters of motion of granular fill in a rotating chamber, which was obtained numerically by the method of discrete elements and experimentally by the method of tracking the behavior of radioactive particles, is presented in [23].

A significant progress has been observed lately in the application of tomographic methods to explore the behavior of filling the closed chambers. However, considerable complexity in their implementation and limited measurement resolution reduce reliability and accuracy of the results obtained.

In this regard, [24] evaluated the complexity and significance of adequate determining of rheological properties of granular media for the case of solving a problem on defining the motion of filling a rotating chamber by analytical method. It was indicated that the rheological characteristics of such media significantly vary depending on the flow type.

The character of motion modes of granular fill in a rotating chamber largely depends on the position and shape of surface in the transition zone from a solid-body motion to the zone of falling and shattering. Such a surface is formed on top of the chamber and defines dynamic parameters of active movable part of the fill. In order to solve the problem on determining such a characteristic element in the flow of array of fill, analytical research methods were mostly applied.

At the same time, a traditional hypothesis on the realization of operational processes when processing granular materials in the drum machines [25] is based on the concept of a separate element of the fill in a chamber, isolated from the surrounding medium. Such element moves under the action only of gravity force $\mathrm{G}$, centrifugal inertia $\mathrm{C}$ and reaction of the limiting surface $\mathrm{N}$ and $\mathrm{T}$ (Fig. 1).

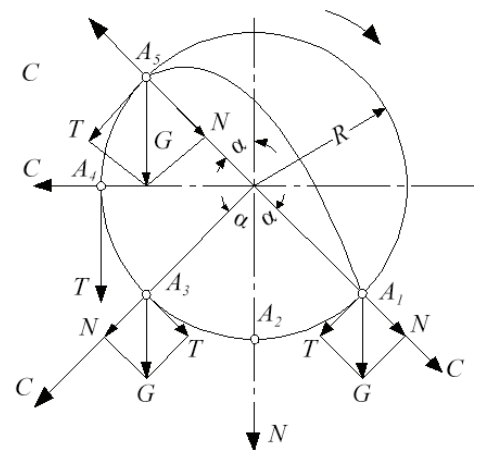

Fig. 1. Trajectory of motion of a granular fill's element in a rotating chamber and the forces applied to it by the traditional hypothesis

According to this hypothesis, the interaction between elements is disregarded. It is considered that elements of the fill are captured by the surface of a rotating chamber until the moment when the gravity forces exceed the centrifugal forces, after which these elements start to move by parabola. Trajectories of elements' motion do not intersect. It is assumed that the fill motion mode is a two-phase «waterfall» with a solid-body zone and the toss and drop zone in the cross section of a chamber. The locus of transition of the fill's elements from the circular to the parabolic trajectories (Fig. 2) is assigned by an auxiliary circle of diameter a

$$
\mathrm{a}=\frac{\mathrm{g}}{\omega^{2}}
$$

where $g$ is the gravitational acceleration, $\omega$ is the angular rotation velocity of a chamber. 


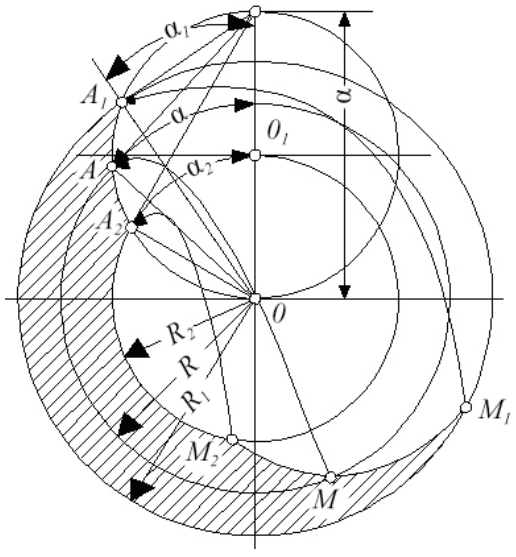

Fig. 2. Locus of transition points of the granular fill's elements in a rotating chamber from circular to parabolic trajectories by the traditional hypothesis

However, the real motion mode of the fill is a three phase one when the quasi solid-body and non-free falling zones in the cross-section of a rotating chamber are complemented by a zone of the shifting layer. The main process of processing the granular materials is implemented in this particular zone.

Meanwhile, the problem on defining the surface of destruction in the solid-body zone, based on the equilibrium of a separate element in the granular fill of a rotating chamber, was considered in [26]. The stressed-strained state of the medium was not examined. An equation for the transition surface was obtained in a simplified statement depending on a limited number of parameters.

[27-31] analytically examined in a static statement the sliding surfaces when considering the carrying capacity of slopes in granular materials, mainly in the application to soils.

Ref. [27] considered a problem on the analytical calculation of non-movable soil slope stability on the sliding surfaces of a simplified circular-cylindrical shape. A method of hypothetical circular sliding surfaces with regard to the soil non-uniformity was applied in [28]. In [29], based on the Mohr theory, authors examined positions of sliplines in a perfect plastic medium. The stability of slopes in granular material when reaching the boundary condition in a static statement was investigated in [30]. [31] explored the boundary stressed-strained state of slopes' stability in a granular medium.

Paper [32], based on the model of pre-boundary elastoplastic deformation, defined the stressed-strained state of a granular medium only at slow rotation of the chamber.

Article [33] analytically in a plastic statement attempted to determine the stressed-strained state of the fill in the form of simplified picture of the motion and velocity field of a shifting layer at low rotation rate.

However, the overwhelming computational difficulties and low reliability of the hardware control restrict effectiveness of the known methods for determining the surface of mode transition in the fill motion. That is why the obtained results of numerical calculations and experiments approach the real modes of motion of the examined medium only by qualitative characteristics and external attributes. By the quantitative indicators, they are substantially divergent.

In view of the aforementioned, an analytic modeling of the required boundary for the case of non-low rotation velocity of a chamber appears to be quite an important applied problem. Of particular interest is taking account of variations in geometric and rheological characteristics within a wide range of variations in the parameters of the system.

\section{The aim and tasks of the study}

The aim of present work is to create a mathematical model for the behavior of a granular fill in the transition from the circular, during the ascent, to the quasi-parabolic, when lowering, trajectories of sustainable motion in the cross-section of a cylindrical chamber that permanently revolves around a horizontal axis. This will allow us to determine dynamic parameters in the motion of a sliding layer of the fill and to predict effectiveness in the implementation of technological processing of a granular material in a rotating chamber.

To accomplish the set aim, the following tasks were to be solved:

- to perform analytical modeling of stress field in the mass of a granular fill in the cross-section of a chamber;

- to establish conditions for disequilibrium in filling the chamber;

- to define the shape and position of the surface of destruction of the quasi solid-body zone in the fill motion;

- to establish effect of the system's parameters on the boundary of transition in the motion zones.

\section{Procedure of examining the stressed-strained state of the fill in a chamber}

4. 1. General conceptual approach to the research technique

A granular fill in a rotating chamber was considered to be a multi-phase polydispersed system with a non-uniform dispersed phase. It was thought that the size of inhomogeneties is much less than at the distance at which the macroscopic or averaged parameters of multiphase medium of the fill substantially changed. A realization of the adopted assumption made it possible to describe a change in the averaged parameters of a multiphase system within representations and based on conventional equations and methods of mechanics of the entire medium. Granular fill of a rotating chamber was considered as a whole medium with parameters, which are averaged by volume and uniformly distributed in the space that a multi-phase medium occupies. Mathematical description of the fill motion was performed by using averaged magnitudes. A method of calculating the stressed-strained state of the fill was employed. The fill flow was thought to be slow with predominance of the forces of plastic origin over the viscous inertial forces. A plastic rheological model of granular medium of the fill was accepted.

\section{2. Applied methods for modeling the behavior of} granular medium of the fill

Subsequent numerical solution of the problem on determining the limit of strength of a solid-body array, at sustainable motion of the granular fill, averaged by volume, in a rotating chamber, is to be found in a plastic statement. Experimental data revealed a relatively large value of the angle of repose in the motion along free surface at a moderate rotation velocity of the chamber. This made it possible to accept a pseudo plastic rheological model of a medium. This model is a particular case in the manifestation of viscoplastic properties of a rheologically-complex fill. 
Shift resistance in the point of filling consists of the resistance caused by internal friction and adhesion and is expressed by a dependence that occurs at disequilibrium $[30,34]$

$$
\left|\tau_{\mathrm{n}}\right|=\sigma_{\mathrm{n}} \operatorname{tg} \varphi+\mathrm{k},
$$

where $\sigma_{\mathrm{n}}$ and $\tau_{\mathrm{n}}$ are the normal and tangent components of pressure, $\mathrm{n}$ is a normal to the sliding surface, $\phi$ is the angle of internal friction, $\mathrm{k}$ is the adhesion coefficient.

A two-dimensional stressed state in point $\mathrm{P}$ of a granular fill is characterized by a general scheme (Fig. 3).

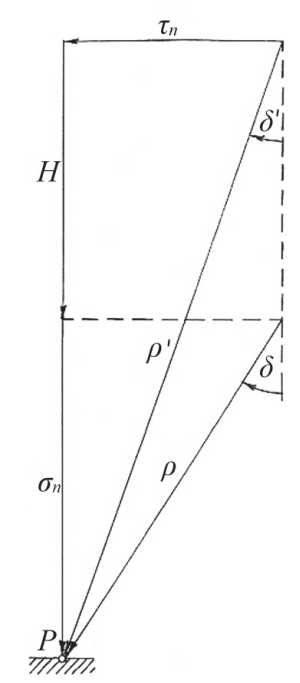

Fig. 3. General scheme of a flat stressed state in the point of filling

In this point, real tension $\mathrm{p}$ and resulting tension $\mathrm{p}^{\prime}$ act. Real tension $\mathrm{p}$ forms angle $\delta$ with normal $\mathrm{n}$ and has normal $\sigma_{\mathrm{n}}$ and tangent $\tau_{\mathrm{n}}$ components. Resulting tension $\mathrm{p}^{\prime}$ forms angle $\delta^{\prime}$ with normal $\mathrm{n}$ and has normal $\sigma_{\mathrm{n}}+\mathrm{H}$ and tangent $\tau_{\mathrm{n}}$ components, where $\mathrm{H}=\mathrm{k} \cdot \operatorname{tg} \varphi$ is the coefficient of temporary resistance to the comprehensive uniform stretching.

Slipping as a result of shift of the medium along the examined elementary area will not take place while maintaining the conditions of boundary equilibrium of the fill

$$
\left|\tau_{\mathrm{n}}\right| \leq\left(\sigma_{\mathrm{n}}+\mathrm{H}\right) \operatorname{tg} \varphi
$$

in this case, $\sigma_{\mathrm{n}} \geq-\mathrm{H}$.

A visual representation of the stressed state in the point of granular fill is defined by a stress diagram (Fig. 4), where $\sigma=\left(\sigma_{\max }+\sigma_{\min }\right) / 2 ; \mathrm{t}=\left(\sigma_{\max }-\sigma_{\min }\right) / 2 ; \sigma_{\max }$ and $\sigma_{\min }$ are the main normal stresses; $\lambda, \mu$ and $v$ are the angles of direction cosines between the normal to the area and main axes.

We can write

$$
\begin{aligned}
& \sigma=\mathrm{p}^{\prime} \frac{\sin \Delta}{\sin \left(\Delta-\kappa_{\mathrm{f}} \delta^{\prime}\right)}, \\
& \lambda=\frac{\left(1-\kappa_{\mathrm{f}}\right) \pi}{4}+\frac{\kappa_{\mathrm{f}} \Delta-\delta^{\prime}}{2}+\mathrm{m} \pi,
\end{aligned}
$$

where $\kappa_{\mathrm{f}}= \pm 1, \mathrm{~m}$ is any integer, $\sin \Delta=\sin \delta^{\prime} / \sin \varphi(|\Delta| \leq \pi / 2)$. Two signs $\kappa_{\mathrm{f}}=-1$ and $\kappa_{\mathrm{f}}=+1$ that are included in these equations correspond to the two stressed states - minimum and maximum.

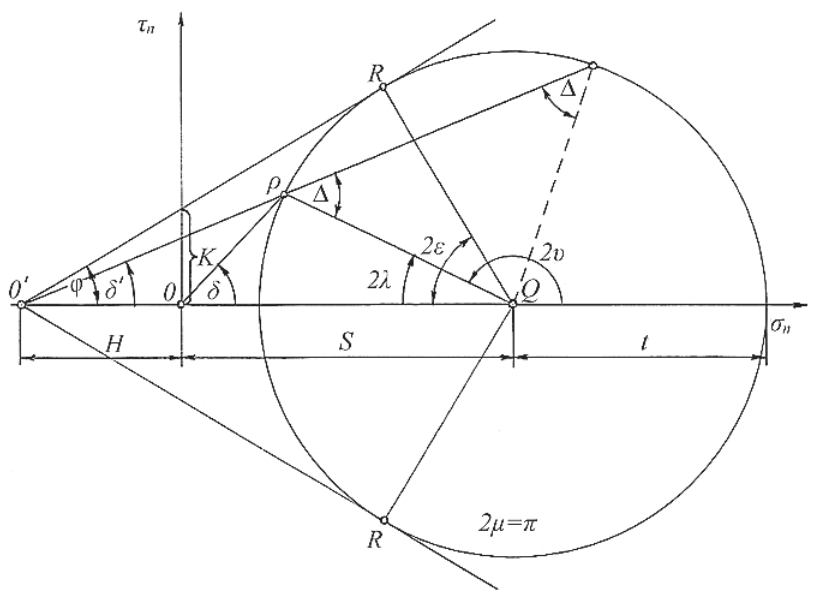

Fig. 4. Stress diagram of a flat stressed state in the point of filling

A rectangular coordinate system is used with a highlighted element with coordinates $\mathrm{x}, \mathrm{y}$ and dimensions $\mathrm{dx}$ and dy (Fig. 5) where $\sigma_{\mathrm{x}}, \sigma_{\mathrm{y}}$ and $\tau_{\mathrm{xy}}=\tau_{\mathrm{yx}}$ are three components of a pressure tensor.

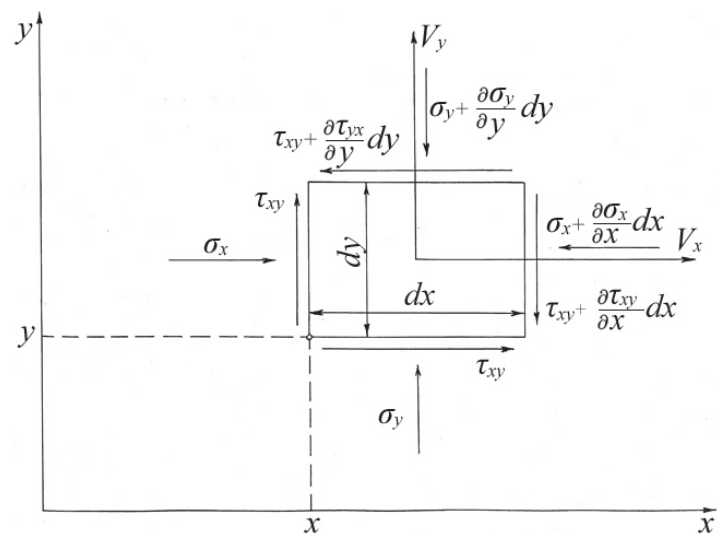

Fig. 5. Schematic of a flat stressed-strained state of the fill medium

In the zone of boundary equilibrium, each point is crossed by two lines of sliding that comprise a system of two families (Fig. 6), where $\Omega$ is the angle between direction $\sigma_{\max }$ and the x axis, $\Omega \pm \varepsilon$ are the inclination angles of sliplines to the $\mathrm{x}$ axis, 1 and 2 are the slip lines.

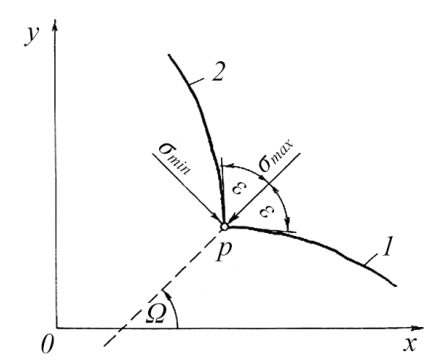

Fig. 6. Directions of slip lines in the zone of flat boundary equilibrium of the fill

Thus, in the zone of boundary equilibrium, through each point in the xy plane (Fig. 6), traces of sliding surfaces form two slip lines. The entire zone of the boundary equilibrium is covered by the two families of slip lines. However, only one 
of the slip lines is active or is a break line. Position of the active family is defined by the direction along which a breach in boundary equilibrium occurs. This direction depends to a large degree on the type and initial conditions of the medium loading.

\section{Results of modeling the fracture surface of a solid- body zone of the fill in a chamber}

Subsequently, we consider the boundary equilibrium of an array of loose granular fill of a cylindrical chamber with radius $\mathrm{R}$ that rotates around a horizontal axis with constant angular velocity $\omega$. A flat free surface of the array, before the onset of shift, is limited by the $\mathrm{x}$ axis and tilted to the horizontal at angle $\alpha$ (Fig. 7 ). At the array's surface, we evenly distributed at constant angle $\delta$ to the normal reduced pressure p, caused by the action of applied centrifugal forces of inertia. Positive value $\delta$, based from the normal to the surface of the array, is assigned in a counterclockwise direction (Fig. 8). Expression for angle $\delta$ can be represented in the form

$$
\delta=\frac{\alpha_{1}}{2}-\beta,
$$

where $\alpha_{1}$ is the lifting angle of the fill in a rotating chamber; $\beta$ is the half of the central angle of a segment cross-section of the fill at rest, which is determined from equation

$$
2 \beta-\sin 2 \beta=2 \pi \kappa,
$$

where $\kappa$ is the degree of filling the chamber with a granular material.

Expression for angle $\alpha$ takes the form

$$
\alpha=\alpha_{1}-\beta+\frac{\pi}{2} .
$$

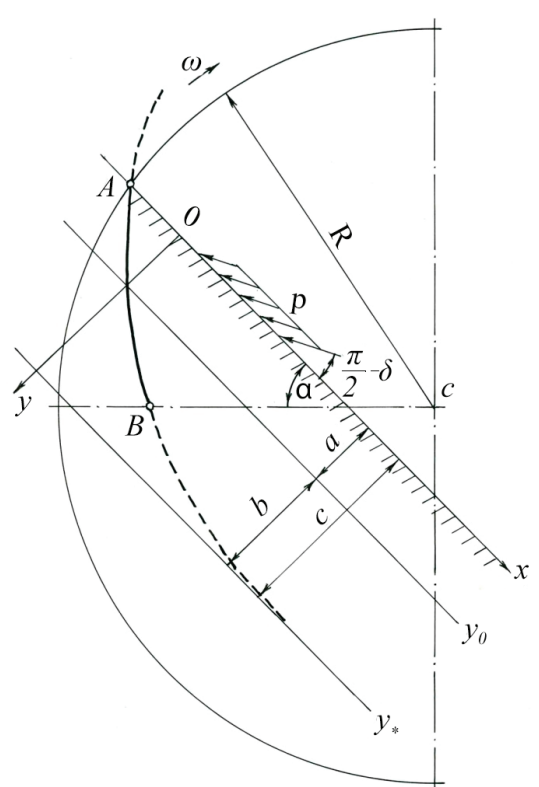

Fig. 7. General estimated scheme of slip lines of the fill

The value of reduced pressure $\mathrm{p}$ is taken for the central part of the array - point S (Fig. 8) that approaches point D at the surface of a chamber. The magnitude of this pressure takes into account the effect of centrifugal, variational and
Coriolis forces of inertia. Additional action of variational forces is caused by the separation of elements from the array with subsequent non-free fall. Additional action of Coriolis forces is caused by relative motion of the slip layer of the fill.

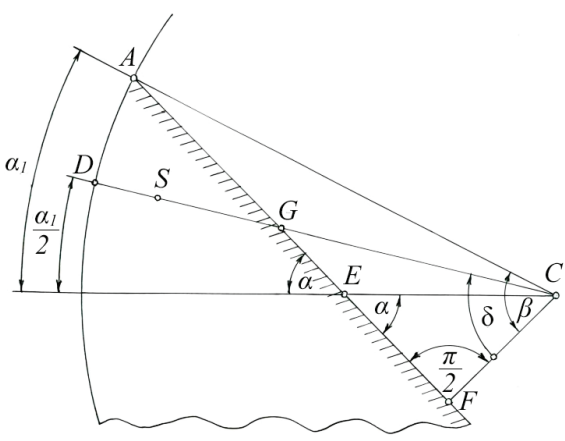

Fig. 8. Scheme of angles for the calculation of slip lines of the fill

The ratio of pressure $\mathrm{p}$ and specific bulk weight of the filler $\gamma$ can be approximately represented by expression

$$
\frac{\mathrm{p}}{\gamma}=\frac{\omega^{2}}{2 \mathrm{~g}}\left(\mathrm{CD}^{2}-\mathrm{CG}^{2}\right) \text {. }
$$

Based on the solution of oblique-angled triangle AGC (Fig. 8) with angles $\angle \mathrm{GAC}=\pi / 2-\beta, \angle \mathrm{CGA}=\pi / 2+\beta-\alpha_{1} / 2$ and $\angle \mathrm{ACG}=\alpha_{1} / 2$, it is possible to write

$$
\mathrm{CG}=\mathrm{R} \frac{\cos \beta}{\cos \left(\beta-\frac{\alpha_{1}}{2}\right)} .
$$

Then relation (3) takes the form

$$
\frac{\mathrm{p}}{\gamma}=\frac{\omega^{2} \mathrm{R}^{2}}{2 \mathrm{~g}}\left\{1-\left[\frac{\cos ^{2} \beta}{\cos ^{2}\left(\beta-\frac{\alpha_{1}}{2}\right)}\right]\right\} .
$$

Normal and tangent components of pressure along the $\mathrm{x}$ axis can be expressed in the form

$$
\begin{aligned}
& \sigma_{y}+H=p \cos \delta, \\
& \tau_{x y}=p \sin \delta .
\end{aligned}
$$

In a general case, stress field in the array is determined by a system of equations of flat boundary equilibrium of a granular medium

$$
\begin{aligned}
& \mathrm{F}_{\mathrm{x}}-\frac{\mathrm{g}}{\gamma}\left(\frac{\partial \sigma_{\mathrm{x}}}{\partial \mathrm{x}}+\frac{\partial \tau_{\mathrm{xy}}}{\partial \mathrm{y}}\right)=0, \\
& \mathrm{~F}_{\mathrm{y}}-\frac{\mathrm{g}}{\gamma}\left(\frac{\partial \sigma_{\mathrm{y}}}{\partial \mathrm{y}}+\frac{\partial \tau_{\mathrm{yx}}}{\partial \mathrm{x}}\right)=0, \\
& \left(\sigma_{\mathrm{x}}-\sigma_{\mathrm{y}}\right)^{2}+4 \tau_{\mathrm{xy}}^{2}=\left(\sigma_{\mathrm{x}}+\sigma_{\mathrm{y}}+2 \mathrm{k} \cdot \operatorname{ctg} \varphi\right)^{2} \sin ^{2} \varphi,
\end{aligned}
$$

where $F_{x}$ and $F_{y}$ are the projections of mass forces. The first and the second equations of the system are differential equations of equilibrium, the third equation is the condition for boundary equilibrium. 
Under condition of the $\mathrm{x}$-axis inclination to the horizontal at angle $\alpha$ :

$\mathrm{F}_{\mathrm{x}}=\gamma \sin \alpha, \mathrm{F}_{\mathrm{y}}=\gamma \cos \alpha$.

Then the stress field that occurs in the examined array does not depend on $\mathrm{x}$ and is described by the differential equations of equilibrium

$$
\begin{aligned}
& \frac{\partial \tau_{x y}}{\partial y}=\gamma \sin \alpha, \\
& \frac{\partial \sigma_{y}}{\partial y}=\gamma \cos \alpha .
\end{aligned}
$$

After integration of equations (5) with regard to (4), it is possible to obtain

$$
\begin{aligned}
& \sigma_{y}+H=p \cos \delta+\gamma y \cos \alpha, \\
& \tau_{x y}=p \sin \delta+\gamma y \sin \alpha .
\end{aligned}
$$

Based on (6), the reduced stress that acts on the inclined lines, parallel to the $\mathrm{x}$ axis, is determined by magnitudes

$$
\begin{aligned}
& \operatorname{tg} \delta_{y}=\frac{p \sin \delta+\gamma y \sin \alpha}{p \cos \delta+\gamma y \cos \alpha}, \\
& \mathrm{p}_{\mathrm{y}}=\mathrm{p} \cos \left(\delta-\delta_{\mathrm{y}}\right)+\gamma \mathrm{y} \cos \left(\alpha-\delta_{\mathrm{y}}\right),
\end{aligned}
$$

where $\mathrm{p}_{\mathrm{y}}$ and $\delta_{\mathrm{y}}$ are the stress and its inclination angle to the normals to the slanted straight line with ordinate y.

By analogy to (2), it is possible to write

$$
\begin{aligned}
& \sigma=\mathrm{p}_{\mathrm{y}} \frac{\sin \Delta_{\mathrm{y}}}{\sin \left(\Delta_{\mathrm{y}}-\kappa_{\mathrm{f}} \delta_{\mathrm{y}}\right)}, \\
& \Omega=\frac{\left(1-\kappa_{\mathrm{f}}\right) \pi}{4}+\frac{\kappa_{\mathrm{f}} \Delta_{\mathrm{y}}-\delta_{\mathrm{y}}}{2}+\mathrm{m} \pi,
\end{aligned}
$$

where

$$
\sin \Delta_{\mathrm{y}}=\sin \delta_{\mathrm{y}} / \sin \varphi\left(\left|\Delta_{\mathrm{y}}\right| \leq \pi / 2\right)
$$

Then the y coordinate is expressed through dy or $\Omega$ in the following way

$$
y=-\frac{p}{\gamma} \frac{\sin \left(\delta-\delta_{y}\right)}{\sin \left(\alpha-\delta_{y}\right)}=-\frac{p}{\gamma} \frac{\sin \delta-\sin \varphi \sin (2 \Omega+\delta)}{\sin \alpha-\sin \varphi \sin (2 \Omega+\alpha)} .
$$

Straight line, along which $\tau_{\mathrm{xy}}=0$ and which satisfies condition $\delta_{\mathrm{y}}=0$, has ordinate (Fig. 7)

$$
\mathrm{a}=\left(\mathrm{y}_{0}\right)=-\frac{\mathrm{p}}{\gamma} \frac{\sin \delta}{\sin \alpha} .
$$

If $\alpha \leq \varphi$, then the boundary equilibrium is possible in all half-plane $0 \leq \mathrm{y} \leq \infty$ since inequality $\left|\delta_{\mathrm{y}}\right| \leq \varphi$ is fulfilled automatically. If $\alpha>\varphi$, then the boundary equilibrium is possible only in some plane $0 \leq \mathrm{y} \leq \mathrm{y} *$, in which inequality $\left|\delta_{\mathrm{y}}\right| \leq \varphi$ is satisfied.

The ordinate that satisfies condition $\delta_{\mathrm{y}}=\varphi$ is (Fig. 7)

$$
c=\left(y_{*}\right)=\frac{p}{\gamma} \frac{\sin (\varphi-\delta)}{\sin (\alpha-\varphi)},
$$

and the width of band $\mathrm{y}_{0} \leq \mathrm{y} \leq \mathrm{y} *$ where $0 \leq \delta_{\mathrm{y}} \leq \varphi$ is equal to

$$
\mathrm{b}=\left(\mathrm{y}_{*}-\mathrm{y}_{0}\right)=\frac{\mathrm{p}}{\gamma} \frac{\sin \varphi \sin (\alpha-\delta)}{\sin \alpha \sin (\alpha-\varphi)} .
$$

In order to determine the slip lines of the examined stress field, it is necessary to apply differential equation

$$
\frac{d y}{d x}=\operatorname{tg}(\Omega \mp \varepsilon) \text {. }
$$

$\mathrm{y}$ is possible to express through $\Omega$ in (7) by using relation

$$
y-a=\left(y-y_{0}\right)=b \sin (\alpha-\varphi) \frac{\sin 2 \Omega}{\sin \alpha \mp \sin \varphi \sin (2 \Omega+\alpha)} .
$$

Then it is possible to obtain after transforms

$$
\frac{\mathrm{dx}}{\mathrm{d} \Omega}=-2 \mathrm{~b} \sin \alpha \sin (\alpha-\varphi) \frac{\sin 2 \Omega \pm \cos \varphi}{[\sin \alpha \mp \sin \varphi \sin (2 \Omega+\alpha)]^{2}}
$$

Equation (8) can be integrated in elementary functions

$$
\begin{aligned}
& \mathrm{x}(\Omega)= \\
& =-2 \mathrm{~b} \sin \alpha \sin (\alpha-\varphi) \frac{\sin 2 \Omega \pm \cos \varphi}{[\sin \alpha \mp \sin \varphi \sin (2 \Omega+\alpha)]^{2}} \mathrm{~d} \Omega+\text { const. }
\end{aligned}
$$

Finally, the coordinates of required slip line AB (Fig. 7) can be represented in the parametric form

$$
y=b \sin (\alpha-\varphi) \frac{\sin 2 \Omega}{\sin \alpha \mp \sin \varphi \sin (2 \Omega+\alpha)},
$$

$$
\begin{aligned}
& \mathrm{x}_{1,2}=\frac{2 \mathrm{~b} \sin \alpha \sin (\alpha-\varphi)}{\sin ^{2} \alpha-\sin ^{2} \varphi} \times \\
& \times\left\{\frac{[ \pm \cos \varphi(\mp \sin \varphi)-\sin \alpha] \cos (2 \Omega+\alpha)}{2[\sin \alpha+(\mp \sin \varphi) \sin (2 \Omega+\alpha)]}+\right. \\
& +\frac{ \pm \cos \varphi \sin \alpha-(\mp \sin \varphi)}{\sqrt{\sin ^{2} \alpha-\sin ^{2} \varphi}} \times \\
& \times \operatorname{arctg}\left[\frac{\sin \alpha \cdot \operatorname{tg}\left(\Omega+\frac{\alpha}{2}\right)+(\mp \sin \varphi)}{\sqrt{\sin ^{2} \alpha-\sin ^{2} \varphi}}\right]- \\
& -\frac{[ \pm \cos \varphi(\mp \sin \varphi)-\sin \alpha] \cos \alpha}{2[\sin \alpha+(\mp \sin \varphi) \sin \alpha]}- \\
& -\frac{ \pm \cos \varphi \sin \alpha-(\mp \sin \varphi)}{\sqrt{\sin ^{2} \alpha-\sin ^{2} \varphi}} \times \\
& \left.\times \operatorname{arctg}\left[\frac{\sin \alpha \cdot \operatorname{tg}\left(\frac{\alpha}{2}\right)+(\mp \sin \varphi)}{\sqrt{\sin ^{2} \alpha-\sin ^{2} \varphi}}\right]\right\} \text {. }
\end{aligned}
$$


A parametric form of the equations derived allows us to define and analyze the coordinates of a slip line, depending on the variation of parameters of the examined system.

\section{Discussion of results of examining the impact of parameters of a filled rotating chamber on the fracture surface of a solid-body zone of the fill}

Mathematical description of the transition boundary position in the motion of granular fill in a rotating chamber, from the circular to the quasi parabolic trajectories, was performed according to a classical scheme with the use of magnitudes averaged by volume. We made an assumption about the slow motion of a loose granular medium with the predominance of forces, plastic in origin, over the viscous inertial forces. This made it possible to obtain equations that approximately establish dependences of the required limit coordinates in the parametric form on the series of parameters of the examined system:

- geometric: radius $\mathrm{R}$ of the chamber and the degree of its filling $\kappa$;

- kinematic: angular rotation velocity of the chamber $\omega$;

- inertial: specific bulk weight of the fill $\gamma$;

- rheological: the angle of internal friction of the fill $\varphi$ and its lifting angle in arotating chamber $\alpha_{1}$.

The advantage of the proposed approach, in comparison with the traditional hypothesis (1), is the possibility to derive such limit from parameters $\mathrm{R}, \kappa, \omega, \gamma, \varphi$ and $\alpha_{1}$. According to (9) and (10), the shape of such a surface is curvilinear non-cylindrical. Instead, according to (1), this limit is of cylindrical shape with a diameter that depends only on $\omega$.

An analysis of (9) and (10) reveals that at increase in the values of parameters $\omega, \gamma, \varphi$ and $\alpha_{1}$ and decrease in the values of $R$ and $\kappa$, location of the transition limit moves away from the free surface of the fill and approaches surface of the chamber.

The disadvantages of the developed algorithm of numerical calculation of the limit include the need for a preliminary experimental determining of ascent angle of the fill in a rotating chamber $\alpha_{1}$. For this purpose, it is possible to use, for example, the method of visual analysis of pictures of motion in the cross section of a chamber.

In the future, it is expedient, with regard to the established characteristics of the limit of breaking the quasi solid-body zone of the fill in a rotating chamber, to investigate, based on analysis of the stressed-strained state, parameters of the shear flow of the fill near a free surface.

\section{Conclusions}

1. We formalized a stress field in the mass of filler in the cross-section of a rotating chamber by using a system of differential equations of flat boundary equilibrium of a granular medium. Equations are obtained that approximately establish positions of the transition limit of particles in the fill from the circular to the quasi parabolic trajectories, depending on the rotation velocity, geometric and rheological parameters of the system.

2. We received a condition for boundary equilibrium in the fill. It is demonstrated that disequilibrium is accompanied by slip layers. The patterns were discovered in the transition of quasi solid-body motion zone of the fill to the zone of nonfree fall and shear flow. It is found that such a transition is accompanied by the destruction of a solid-body zone at the border, which is a slip line of the picture of motion of plastic medium in the cross-section of a chamber.

3. We defined a position and shape of slip lines in the stress field of the fill. It is established that the breaking limit of a solid-body zone in the fill is a curvilinear non-cylindrical surface. It was found that the position of the extreme top line in the transition coincides with the surface of the chamber and is determined by ascent angle of the fill.

4. It is established that the shape and position of the transition limit depend on the magnitude of radius $\mathrm{R}$, degree of filling $\kappa$ and angular rotation velocity of the chamber $\omega$, specific bulk weight $\gamma$ and the angle of internal friction $\varphi$ of the fill and its ascent angle in a rotating chamber $\alpha_{1}$. It was found that at increase in the values of parameters $\omega, \varphi, \gamma$ and $\alpha_{1}$ and decrease in $R$ and $\kappa$, position of the transition limit approaches a surface of the chamber.

\section{References}

1. Pershyn, V. F. Pererabotka sypuchykh materyalov v mashynakh barabannoho typa [Text] / V. F. Pershyn, V. H. Odnolko, S. V. Pershyna. - Moscow: Mashynostroenye, 2009. - 220 p.

2. HOST 27120-86. Pechy khymycheskykh proyzvodstv s vrashchaiushchymysia barabanamy obshcheho naznachenyia. Osnovnye parametry y razmery [Text]. - Moscow: Yzd-vo standartov, 1992. - 17 p.

3. HOST 11875-86. Apparaty teploobmennye s vrashchaiushchymysia barabanamy obshcheho naznachenyia. Kholodylnyky. Osnovnye parametry y razmeruy [Text]. - Moscow: Yzd-vo standartov, 1988. - 8 p.

4. HOST 27134-86. Apparaty sushylnye s vrashchaiushchymysia barabanamy. Osnovnye parametry y razmery [Text]. - Moscow: Yzd-vo standartov, 2002. - 4 p.

5. HOST 10141-91. Melnytsy sterzhnevye y sharovye. Obshchye tekhnycheskye trebovanyia [Text]. - Moscow: Yzd-vo standartov, 1991. $-19 \mathrm{p}$.

6. HOST 12367-85. Melnytsy trubnye pomolnykh ahrehatov. Obshchye tekhnycheskye uslovyia [Text]. - Moscow: Yzd-vo standartov, 1986. $-13 \mathrm{p}$.

7. Naumenko, Yu. V. The antitorque moment in a partially filled horizontal cylinder [Text] / Yu. V. Naumenko // Theoretical Foundations of Chemical Engineering. - 1999. - Vol. 33, Issue 1. - P. 91-95.

8. Naumenko, Yu. V. Determination of rational rotation speeds of horizontal drum machines [Text] / Yu. V. Naumenko // Metallurgical and Mining Industry. - 2000. - Issue 5. - P. 89-92. 
9. Arntz, M. M. H. D. Granular mixing and segregation in a horizontal rotating drum: A simulation study on the impact of rotational speed and fill level [Text] / M. M. H. D. Arntz, W. K. den Otter, W. J. Briels, P. J. T. Bussmann, H. H. Beeftink, R. M. Boom // AIChE Journal. - 2008. - Vol. 54, Issue 12. - P. 3133-3146. doi: 10.1002/aic.11622

10. Bonamy, D. Euler-like modelling of dense granular flows: application to a rotating drum [Text] / D. Bonamy, P.-H. Chavanis, P.-P. Cortet, F. Daviaud, B. Dubrulle, M. Renouf // The European Physical Journal B. - 2009. - Vol. 68, Issue 4. - P. 619-627. doi: 10.1140/epjb/e2009-00123-6

11. Yin, H. Numerical simulation of three-dimensional unsteady granular flows in rotary kiln [Text] / H. Yin, M. Zhang, H. Liu // Powder Technology. - 2014. - Vol. 253. - P. 138-145. doi: 10.1016/j.powtec.2013.10.044

12. Arntz, M. M. H. D. Segregation of granular particles by mass, radius, and density in a horizontal rotating drum [Text] / M. M. H. D. Arntz, H. H. Beeftink, W. K. den Otter, W. J. Briels, R. M. Boom // AIChE Journal. - 2013. - Vol. 60, Issue 1. P. 50-59. doi: 10.1002/aic.14241

13. Marigo, M. Discrete Element Method (DEM) for Industrial Applications: Comments on Calibration and Validation for the Modelling of Cylindrical Pellets [Text] / M. Marigo, E. H. Stitt // KONA Powder and Particle Journal. - 2015. - Vol. 32, Issue 0. P. 236-252. doi: 10.14356/kona.2015016

14. Hung, C.-Y. Granular flow regimes in rotating drums from depth-integrated theory [Text] / C.-Y. Hung, C. P. Stark, H. Capart // Physical Review E. - 2016. - Vol. 93, Issue 3. doi: 10.1103/physreve.93.030902

15. Yang, S. DEM study of granular flow characteristics in the active and passive regions of a three-dimensional rotating drum [Text] / S. Yang, A. Cahyadi, J. Wang, J. W. Chew // AIChE Journal. - 2016. - Vol. 62, Issue 11. - P. 3874-3888. doi: 10.1002/aic.15315

16. Chou, H.-T. Cross-sectional and axial flow characteristics of dry granular material in rotating drums [Text] / H.-T. Chou, C.-F. Lee // Granular Matter. - 2008. - Vol. 11, Issue 1. - P. 13-32. doi: 10.1007/s10035-008-0118-y

17. Dube, O. Dynamics of non-spherical particles in a rotating drum [Text] / O. Dube, E. Alizadeh, J. Chaouki, F. Bertrand // Chemical Engineering Science. - 2013. - Vol. 101. - P. 486-502. doi: 10.1016/j.ces.2013.07.011

18. Alizadeh, E. Characterization of Mixing and Size Segregation in a Rotating Drum by a Particle Tracking Method [Text] / E. Alizadeh, O. Dube, F. Bertrand, J. Chaouki // AIChE Journal. - 2013. - Vol. 59, Issue 6. - P. 1894-1905. doi: 10.1002/aic.13982

19. Morrison, A. J. The shape and behaviour of a granular bed in a rotating drum using Eulerian flow fields obtained from PEPT [Text] / A. J. Morrison, I. Govender, A. N. Mainza, D. J. Parker // Chemical Engineering Science. - 2016. - Vol. 152. - P. 186-198. doi: 10.1016/j.ces.2016.06.022

20. Tupper, G. B. Testing of a new dynamic Ergun equation for transport with positron emission particle tracking [Text] / G. B. Tupper, I. Govender, D. N. De Klerk, M. C. Richter, A. N. Mainza // AIChE Journal. - 2015. - Vol. 62, Issue 3. - P. $939-946$. doi: 10.1002/aic.15081

21. Rasouli, M. Investigating the dynamics of cylindrical particles in a rotating drum using multiple radioactive particle tracking [Text] / M. Rasouli, O. Dube, F. Bertrand, J. Chaouki // AIChE Journal. - 2016. - Vol. 62, Issue 8. - P. 2622-2634. doi: 10.1002/aic.15235

22. Govender, I. A positron emission particle tracking investigation of the scaling law governing free surface flows in tumbling mills [Text] / I. Govender, M. C. Richter, A. N. Mainza, D. N. De Klerk // AIChE Journal. - 2016. - Vol. 63, Issue 3. - P. 903-913. doi: 10.1002/aic.15453

23. Alizadeh, E. Comparison of DEM results and Lagrangian experimental data for the flow and mixing of granules in a rotating drum [Text] / E. Alizadeh, F. Bertrand, J. Chaouki // AIChE Journal. - 2013. - Vol. 60, Issue 1. - P. 60-75. doi: 10.1002/aic.14259

24. Govender, I. Granular flows in rotating drums: A rheological perspective [Text] / I. Govender // Minerals Engineering. - 2016. Vol. 92. - P. 168-175. doi: 10.1016/j.mineng.2016.03.021

25. Andreev, S. E. Droblenye, yzmelchenye y hrokhochenye poleznykh yskopaemykh [Text] / S. E. Andreev, V. A. Perov, V. V. Zverevych. - Moscow: Nedra, 1980. - 415 p.

26. Sverdlyk, H. Y. O strukture sechenyia materyala, peresypaiushchehosia vo vrashchaiushchemsia barabane [Text] / H. Y. Sverdlyk, H. H. Hryhorev // Yzv. vuzov. Chern. Metallurhyia. - 1977. - Issue 8. - P. 169-172.

27. Tsytovych, N. A. Mekhanyka hruntov [Text] / N. A. Tsytovych. - Moscow: Vyschaya shkola, 1983. - 288 p.

28. Kharr, M. E. Osnovy teoretycheskoi mekhanyky hruntov [Text] / M. E. Kharr. - Moscow: Hosstroiyzdat, 1971. - 320 p.

29. Naday, A. Plastychnost y razrushenye tverdykh tel. Vol. 2 [Text] / A. Naday. - Moscow: Yzd-vo Myr, 1969. - 864 p.

30. Sokolovskyi, V. V. Statyka sypuchei sredy [Text] / V. V. Sokolovskyi. - Moscow: Vyschaya shkola, 1960. - 241 p.

31. Kondratev, D. S. Upruhoplastycheskoe deformyrovanye y predelnoe ravnovesye sypuchykh sred [Text] / D. S. Kondratev, P. V. Stetsenko, Y. V. Shyrko // Prykladnaia matematyka y mekhanyka. - 2005. - Vol. 69, Issue 1. - P. 117-134.

32. Bushmanova, O. P. Dopredelnoe plastycheskoe deformyrovanye sypuchei sredy vo vrashchaiushchemsia barabane [Text] / O. P. Bushmanova, O. A. Revuzhenko // Fyzyko-tekhnycheskye problemy razrabotky poleznykh yskopaemykh. - 2004. - Issue 6. - P. 58-67.

33. Slanevskyi, A. V. Osnovy mekhanyky sypuchei sredy vo vrashchaiushchykhsia pechakh y melnytsakh [Text] / A. V. Slanevskyi. Sankt-Peterburg, 1996. - 238 p.

34. Henyev, H. A. Voprosy dynamyky sypuchei sredy [Text] / H. A. Henyev. - Moscow Hosstroiyzdat, 1958. - 122 p. 